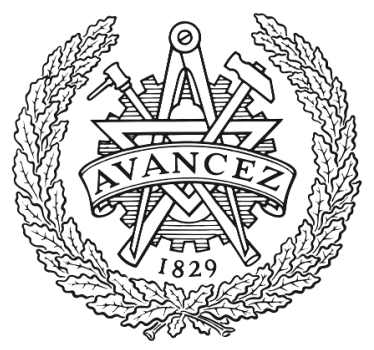

CHALMERS

UNIVERSITY OF TECHNOLOGY

\title{
A parallelized nanofluidic device for high-throughput optical dna mapping of bacterial plasmids
}

Downloaded from: https://research.chalmers.se, 2023-04-26 14:53 UTC

Citation for the original published paper (version of record):

Kesarimangalam, S., Lin, Y., Sewunet, T. et al (2021). A parallelized nanofluidic device for high-throughput optical dna mapping of bacterial plasmids. Micromachines, 12(10).

http://dx.doi.org/10.3390/mi12101234

N.B. When citing this work, cite the original published paper. 


\title{
Article \\ A Parallelized Nanofluidic Device for High-Throughput Optical DNA Mapping of Bacterial Plasmids
}

\author{
Sriram KK ${ }^{1,+}\left(\mathbb{D}\right.$, Yii-Lih Lin ${ }^{1,+}$, Tsegaye Sewunet ${ }^{2}$, Marie Wrande ${ }^{3}$, Linus Sandegren ${ }^{3}$, Christian G. Giske ${ }^{2,4}$ \\ and Fredrik Westerlund $1, * \mathbb{C}$ \\ 1 Division of Chemical Biology, Department of Biology and Biological Engineering, Chalmers University of \\ Technology, 41296 Gothenburg, Sweden; sriramk@chalmers.se (S.K.); yiilih@gmail.com (Y.-L.L.) \\ 2 Division of Clinical Microbiology, Department of Laboratory Medicine, Karolinska Institute, \\ 14152 Stockholm, Sweden; tsegaye.sewunet@ki.se (T.S.); christian.giske@ki.se (C.G.G.) \\ 3 Department of Medical Biochemistry and Microbiology, Uppsala University, 75237 Uppsala, Sweden; \\ marie.wrande@imbim.uu.se (M.W.); linus.sandegren@imbim.uu.se (L.S.) \\ 4 Clinical Microbiology, Karolinska University Hospital, 17176 Stockholm, Sweden \\ * Correspondence: fredrikw@chalmers.se; Tel.: +46-31-772-3049 \\ + These authors contributed equally.
}

check for

updates

Citation: KK, S.; Lin, Y.-L.; Sewunet,

T.; Wrande, M.; Sandegren, L.; Giske,

C.G.; Westerlund, F. A Parallelized

Nanofluidic Device for

High-Throughput Optical DNA

Mapping of Bacterial Plasmids.

Micromachines 2021, 12, 1234. https:/ /

doi.org/10.3390/mi12101234

Academic Editor:

Nam-Trung Nguyen

Received: 14 September 2021

Accepted: 8 October 2021

Published: 11 October 2021

Publisher's Note: MDPI stays neutral with regard to jurisdictional claims in published maps and institutional affiliations.

Copyright: (C) 2021 by the authors. Licensee MDPI, Basel, Switzerland. This article is an open access article distributed under the terms and conditions of the Creative Commons Attribution (CC BY) license (https:/ / creativecommons.org/licenses/by/ $4.0 /)$.

\begin{abstract}
Optical DNA mapping (ODM) has developed into an important technique for DNA analysis, where single DNA molecules are sequence-specifically labeled and stretched, for example, in nanofluidic channels. We have developed an ODM assay to analyze bacterial plasmids-circular extrachromosomal DNA that often carry genes that make bacteria resistant to antibiotics. As for most techniques, the next important step is to increase throughput and automation. In this work, we designed and fabricated a nanofluidic device that, together with a simple automation routine, allows parallel analysis of up to 10 samples at the same time. Using plasmids encoding extended-spectrum beta-lactamases (ESBL), isolated from Escherichia coli and Klebsiella pneumoniae, we demonstrate the multiplexing capabilities of the device when it comes to both many samples in parallel and different resistance genes. As a final example, we combined the device with a novel protocol for rapid cultivation and extraction of plasmids from fecal samples collected from patients. This combined protocol will make it possible to analyze many patient samples in one device already on the day the sample is collected, which is an important step forward for the ODM analysis of plasmids in clinical diagnostics.
\end{abstract}

Keywords: nanofluidics; multiplexing; optical DNA mapping; plasmids; antibiotic resistance

\section{Introduction}

Optical DNA mapping (ODM) using fluorescence imaging of single long DNA molecules, pioneered by David Schwartz and others in the early 1990s [1,2], has now developed into a versatile tool to study genomic DNA. Early work involving DNA mapping was performed by stretching fluorescently labelled single DNA molecules on a positively charged or hydrophobic glass surface [3-5]. Although simple to use, the surface stretching of DNA molecules had drawbacks, in particular with non-uniform DNA stretching. The advent of micro- and nanofluidic devices opened a new possibility of stretching DNA molecules in highly confined environments, providing the opportunity to manipulate single DNA molecules that are not deposited on a surface [6-9].

Early studies of DNA molecules in nanochannels focused primarily on understanding the physics of confined DNA [9-11]. Soon after, research focusing on targeting the underlying DNA sequence was demonstrated, for example the interaction of the LacI repressor with specific sites on $\lambda$-DNA [12]. This, in turn, opened the possibility to use nanofluidic channels for ODM studies of DNA $[13,14]$. Various enzymatic labeling schemes, such as nick labeling [15], nick-flap labeling [16], and methyltransferase labeling [17], have 
been established and used successfully for ODM in nanochannels. We have developed an enzyme-free ODM assay, based on one-step competitive binding that creates an emission intensity variation along the DNA molecule $[14,18]$. For this, the AT-specific drug netropsin and the fluorescent dye YOYO-1 are added to the DNA at the same time, with netropsin:YOYO-1 ratios around 100:1. Netropsin binds to AT-rich regions, leaving the non-specific YOYO-1 to bind primarily to the GC-rich regions, thus creating an intensity variation along the DNA, a "DNA barcode" [14]. This labeling protocol has proved to be useful for various applications, such as plasmid characterization $[19,20]$ and typing of bacteria [21], as well as human genome analysis [22].

According to the World Health Organization (WHO), antimicrobial resistance (AMR) is one of the top ten global threats to human health. AMR imposes a huge present and future burden on global health and economy and requires immediate attention to the development of new diagnostic tools and antibiotics [23]. One key area where competitive binding-based ODM has been successfully used is the study of plasmids, circular DNA molecules not part of the bacterial chromosome, that play an important role in the spread of AMR. By combining the ODM technique with Cas9-mediated identification of resistance genes, the method can determine the number of different plasmids in a sample, their size, on which plasmid a certain resistance gene is located and also use the ODM barcode to identify and trace plasmids [20]. Our methodology has proven to be useful in understanding the role of plasmid conjugation, for example, in hospital outbreaks and recurring urinary tract infections [19,24-27].

To use the assay in a clinical microbiology lab, it is necessary to investigate hundreds of samples per day. In our previous studies, we used a setup consisting of a single set of nanochannels where the experiments for one sample can be completed in approximately one hour. This means that, on a typical workday, up to eight samples could be analyzed.

In this study, we developed a nanofluidic device with the capability to perform ODM on ten different samples at the same time and, with the help of a simple pressure pump and epi-fluorescence microscope, we were able to automate the image acquisition process, thus minimizing the time spent by the researcher in collecting the data. We demonstrate the principle of the device using model DNA. We then turn to the analysis of bacterial plasmids containing important resistance genes from different bacterial species. Finally, we combine the assay with a rapid protocol for extracting plasmids from fecal samples, which is an important step towards clinical use of the technique.

\section{Materials and Methods}

\subsection{Nanofluidics and System Automation}

The nanochannels are of the dimensions of $100 \times 150 \mathrm{~nm}^{2}$ (width $\times$ height) and there are 400 nanochannels in each set (Figure 1). Each nanochannel set is connected to their own inlet microchannel and a shared outlet microchannel (drain). The nanochannels were fabricated with e-beam lithography, followed by the fabrication of microchannels with standard photolithography. Sample loading holes were etched via a deep-RIE process and wafer scale fusion bonding was performed to obtain the micro- and nanoconfinements; the wafer was finally diced to obtain the individual chips $[10,28]$. The chips were then mounted on an acrylic chuck, allowing pre-loading of the sample solutions. This entire setup was custom-designed to fit on an epi-fluorescence microscope (Zeiss AxioObserver.Z1, Carl Zeiss AG, Jena, Germany) and has valves to apply $\mathrm{N}_{2}$-pressure with the help of a tabletop pressure pump (Elveflow OB1 MK3, Paris, France). The setup was automated using a simple program written within the Elveflow software, which was then designed to trigger the EMCCD camera (Andor Ixon 888, Oxford Instruments, Abingdon, UK) to collect images. The Zeiss imaging software (Zen pro blue edition) was programmed to collect images (20 frames, $100 \mathrm{~ms}$ per frame) by moving the microscope stage to designated locations, thereby collecting one image from each of the ten nanochannel modules. Then, the pump flushes the DNA molecules out and brings new molecules in for the next set of images to be taken. This process is repeated until a sufficient amount of data is collected. 
(a)

(b)

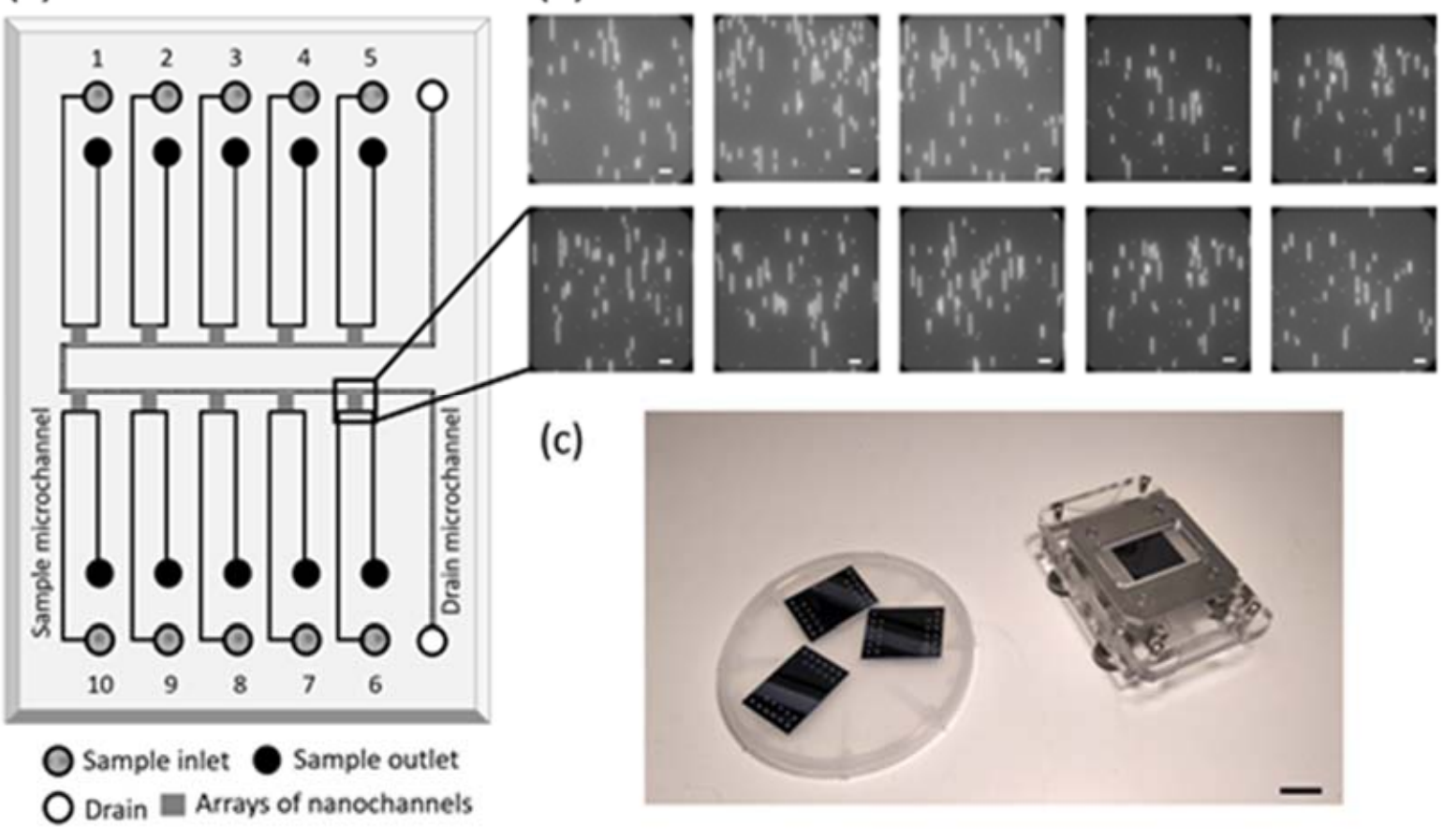

Figure 1. (a) Schematics of the multiplexed nanofluidic chip with inlet, outlet and drain. (b) Fluorescence images of single DNA molecules obtained simultaneously from the ten different nanochannel modules of the chip. Scale bar: $15 \mu \mathrm{m}$. (c) Image showing the chips and the chip holder enabling automation of pressure-driven flow and ODM using an epi-fluorescence microscope. Scale bar: $20 \mathrm{~mm}$.

\subsection{Sample Preparation}

\subsection{1. $\lambda$-DNA at Different Ionic Strengths}

For the experiments at different ionic strengths, $5 \mu \mathrm{M} \lambda$-DNA (48502 bp, New England Biolabs, Ipswich, MA, USA) was mixed with $2 \mu \mathrm{M}$ YOYO (Invitrogen, Waltham, MA, USA) and $520 \mu \mathrm{M}$ netropsin (Sigma-Aldrich, St. Louis, MO, USA) in Tris-BorateEDTA buffer (TBE, Sigma-Aldrich, St. Louis, MO, USA); the samples were incubated at $50{ }^{\circ} \mathrm{C}$ for $30 \mathrm{~min}$ and diluted in MilliQ water to obtain the different ionic strengths. 3\% $(v / v) \beta$-mercaptoethanol (Sigma-Aldrich, St. Louis, MO, USA) was added to suppress photonicking and photobleaching.

\subsubsection{Plasmid Samples for ODM}

Bacterial strains were cultured for $12-16 \mathrm{~h}$ in LB broth supplemented with ampicillin $(30 \mu \mathrm{g} / \mathrm{mL})$ and plasmids were extracted using a NucleoBond Xtra Midi Kit (MachereyNagel GmbH, Düren, Germany), according to the manufacturer's instructions. The eluted DNA was precipitated with $70 \%$ isopropanol and reconstituted with TE buffer (Sigma-Aldrich, St. Louis, MO, USA). The plasmids were treated by either Cas9 (PNA Bio, Thousand Oaks, CA, USA) with tracrRNA (Dharmacon Inc., Lafayette, CO, USA) and crRNA (Dharmacon Inc., Lafayette, CO, USA), targeting specific antibiotic resistance genes (bla $a_{\mathrm{CTX}-\mathrm{M}-14}$ or bla $\left.a_{\mathrm{CTX}-\mathrm{M}-15}\right)$, or just the tracrRNA, without crRNA as control, as shown in the proof-of-concept experiments in Section 3.4. The sequences of the RNA targeting the $b l a_{\mathrm{CTX}-\mathrm{M}-14}$ and $b l a_{\mathrm{CTX}-\mathrm{M}-15}$ genes were $5^{\prime}$ AGAGAGCCGCCGCGATGTGC3' and 5'CCGTCGCGATGTATTAGCGT3', respectively. After the Cas9 reaction, the plasmids were mixed with $\lambda$-DNA as internal size reference and then fluorescently stained with YOYO-1 and netropsin. The molar ratio of YOYO-1 to DNA was 1:2, while that of netropsin to YOYO-1 was 70:1; the staining was performed in 0.5x TBE buffer for $30 \mathrm{~min}$ at $50{ }^{\circ} \mathrm{C}$. The samples were then diluted to $0.05 \mathrm{x}$ TBE to optimize the DNA stretching in the 
nanochannels [13]. B-mercaptoethanol was added at 3\% $(v / v)$ to suppress photonicking and photobleaching.

\subsubsection{Clinical Fecal Samples}

Five fecal samples (F1-F5) known to contain extended-spectrum beta-lactamaseproducing Enterobacterales were collected. The samples were inoculated in $100 \mathrm{~mL}$ of LB broth supplemented with ampicillin $(30 \mu \mathrm{g} / \mathrm{mL})$ and incubated at $37^{\circ} \mathrm{C}$ in a shaking incubator (300 rpm) for $4 \mathrm{~h}$. Plasmid extraction was performed using the NucleoBond Xtra Midi (Macherey Nagel GmbH, Düren, Germany) plasmid extraction and purification kit, as in Section 2.2.2.

\subsection{Data Analysis}

The images collected were first converted into multi-TIFF files. The data obtained from each nanochannel module were separated, to process data from the different samples independently. The image data were then processed to identify fluorescent DNA molecules and their corresponding parameters, including size and the sequence-specific barcodes, as well as the potential presence of resistance genes (bla $a_{\mathrm{CTX}-\mathrm{M}-14}$ or $\left.b l a_{\mathrm{CTX}-\mathrm{M}-15}\right)$. More details on image analysis for ODM has been discussed in our earlier studies [18,20,29]. Briefly, the identified DNA molecules were first sub-grouped by their mean intensity and sizes, compared with $\lambda$-DNA as a reference. Sub-groups of DNA molecules that are twice brighter than $\lambda$-DNA are circular plasmids [30]. Sub-groups of linearized plasmids typically have similar intensity as $\lambda$-DNA and their sizes are 1.8 times longer than their circular counterparts $[13,30]$. Sub-grouped linearized DNA molecules with similar sizes and intensities were then compared for barcode similarity using Pearson cross correlation and merged to a consensus barcode. The barcodes were further used for comparison among isolates (using a $p$-value approach $[27,29]$ ) and for confirming the presence of resistance genes by identifying consensus double-stranded breaks by Cas 9 .

For the comparison of experimental barcodes with long-read sequencing in Section 3.4, FASTA files were converted into a "barcode" based on the binding affinity of YOYO-1 and netropsin to the underlying sequence. The entire procedure has been discussed in detail in our earlier work [18].

\section{Results and Discussion}

\subsection{Nanofluidic Device}

In this work, we used standard semiconductor fabrication methods to make our devices [10]. To start with, computer-aided designing (AutoCAD 2020, Autodesk Inc. San Rafael, CA, USA) was used to prepare the design layout. Nanochannels, microchannels and sample loading holes were designed and the dimensions were chosen to fit the acrylic sample holder on which the fluidic device was mounted, enabling $\mathrm{N}_{2}$ pressure-driven flow of DNA molecules from the sample loading holes to the nanochannels and fluorescence imaging of the stretched DNA molecules in the nanochannels.

Each device consists of ten microfluidic channels, each having an inlet and an outlet to assist sample loading and manipulation of DNA molecules in the microchannels (Figure 1). A common drain-microchannel connects the other end of all the ten sets of nanochannels. The nanochannel sets were designed with the travelling distance of the microscope objective in mind and to minimize out-of-focus issues when the objective automatically moves from one nanochannel set to the next. A total of 400 parallel nanochannels allows tens of DNA molecules to be stretched at the same time and each nanochannel set spans over an area of $300 \times 500 \mu^{2}$, which makes it possible to image DNA molecules in different regions of the same nanochannel set. 


\subsection{Automation of Pressure-Driven Flow and Imaging}

The entropic barrier between the microchannels and the nanochannels allows the DNA to be preconcentrated in front of the nanochannels at a low applied pressure (400 mbar) in order to maximize the number of DNA molecules per field of view (see Materials and Methods). After preconcentration, the DNA molecules were pushed into nanochannels with a short pulse of high pressure ( $2000 \mathrm{mBar}, 800 \mathrm{~ms})$, sufficient to overcome the entropic barrier and short enough to keep the DNA molecules within the $500 \mu \mathrm{m}$ long nanochannels. The pressure cycles to flush DNA through the microchannels, preconcentrate at the entrance of the nanochannels and push into the nanochannels were repeated and followed by automated imaging (see Materials and Methods).

To start with, we performed an experiment to evaluate the effect of preconcentration time on the number of DNA molecules obtained per image in our setup. We used preconcentration times from $30 \mathrm{~s}$ to $2 \mathrm{~min}$ and found that the number of $\lambda$-DNA molecules per image increased linearly with time. For 2 min of preconcentration, we were able to image $\sim 60 \lambda$-DNA molecules per image (Figure 2a). Increasing the preconcentration time further led to that the channels were too crowded with DNA to allow single DNA molecules to be imaged. It is worth noting that the starting DNA concentration and the image field of view also contributes to the number of DNA molecules obtained per image. For all further experiments, a preconcentration time of $2 \mathrm{~min}$ was used.
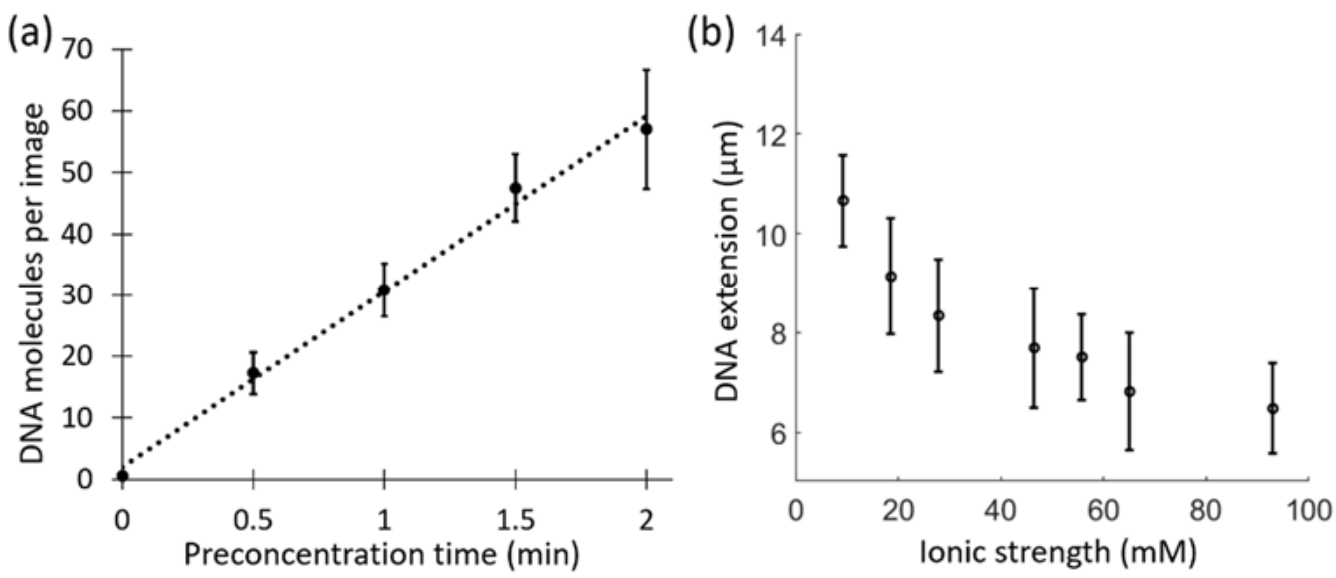

Figure 2. (a) The number of $\lambda$-DNA molecules collected per image with increasing preconcentration time. Error bars are the standard deviations from five images per time point. (b) $\lambda$-DNA extension at seven different ionic strengths measured simultaneously. Each point consists of data for at least 100 molecules. Error bars are standard deviations.

\subsection{DNA Stretching at Varying Ionic Strengths}

With an optimized automation procedure for DNA accumulation and image acquisition, next, we performed a proof-of-concept experiment with $\lambda$-DNA molecules at different ionic strengths. $\lambda$-DNA in TBE buffer at varying ionic strengths (between $10 \mathrm{mM}$ and $100 \mathrm{mM}$ ) was loaded into the different nanochannel modules of the device. The independent nanochannel modules made it possible to study all the different ionic strength conditions at the same time in a single experiment. Images were collected for each ionic strength and the extensions of the DNA molecules were determined from at least $100 \lambda$ DNA molecules at each ionic strength. We found that the DNA stretching, as expected, decreased with the increase in ionic strength (Figure 2b [31-33]).

\subsection{Proof-of-Concept ODM Experiment}

Next, we turned to demonstrating ODM of plasmids carrying the antibiotic resistance gene $b l a_{\mathrm{CTX}-\mathrm{M}-15}$. We selected isolates that were part of a previously published study, where the aim was to characterize plasmids during an outbreak of extended-spectrum $\beta$-lactamase (ESBL)-producing Enterobacteriaceae at a Swedish neonatal intensive care unit [19]. From 
this set of isolates, we picked two ESBL-producing E. coli (ESBL-EC) isolates (P3E1 and P6E1) that did not carry the bla ${ }_{\mathrm{CTX}-\mathrm{M}-15}$ gene of interest on a plasmid and three ESBLproducing K. pneumoniae (ESBL-KP) isolates (KP-P3, -P4 and -P5) with the bla $a_{\mathrm{CTX}-\mathrm{M}-15}$ gene on a plasmid. For all five isolates, two samples were loaded in separate nanochannel modules in the multiplexed device, one treated with Cas 9 targeting the bla $a_{\mathrm{CTX}-\mathrm{M}-15}$ gene and one without. P3E1 and P6E1 had plasmids of identical sizes ( 130 kb). KP-P3, KP-P4 and KP-P5 each had two plasmids, one of identical size in all isolates $(\sim 80 \mathrm{~kb}$, represented by the dark gray-shaded bars in Figure 3a) and one much larger that varied in size among the isolates (represented by the light gray bars in Figure 3a). After the Cas9 restriction, we found that the isolates P3E1 and P6E1 showed no plasmids linearized by Cas9, in line with the fact that the plasmids found in these isolates did not carry the bla $a_{\text {CTX-M-15 }}$ gene [19]. However, for the isolates KP-P3, KP-P4 and KP-P5, we identified the bla $a_{\mathrm{CTX}-\mathrm{M}-15}$ gene on the $\sim 80 \mathrm{~kb}$ plasmid, in accordance with our previously reported results [19]. A comparison of the barcode between the plasmids in these three isolates also showed that they were identical and that the location of the $b a_{\mathrm{CTX}-\mathrm{M}-15}$ gene agreed with long-read sequencing (Figure 3b).
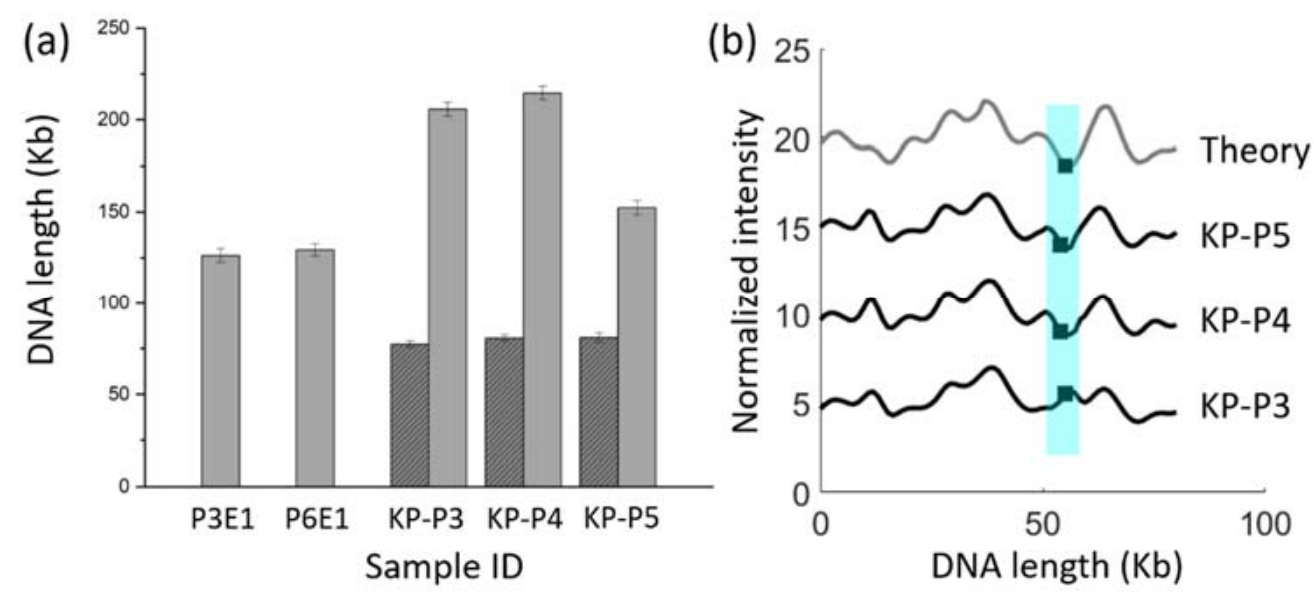

Figure 3. (a) Lengths of plasmids found in the five different isolates. Dark gray-shaded bars represent plasmids where the $b a_{\mathrm{CTX}-\mathrm{M}-15}$ gene was identified. (b) Barcodes of $\sim 80 \mathrm{~kb}$ plasmids with the $b l a_{\mathrm{CTX}-\mathrm{M}-15}$ gene in the KP-P3, KP-P4 and KP-P5 isolates (black), compared to the theoretical barcode generated from long-read sequencing (gray). Black squares within the highlighted region represent the position of the $b l a_{\mathrm{CTX}-\mathrm{M}-15}$ gene.

\subsection{Identification of Multiple Resistance Genes on Plasmids}

To further demonstrate the usefulness of the multiplexed device, we extended our study to detect different resistance genes at the same time. For this, we used isolates M1, M2 and M3, where we expected to have plasmids carrying either of the two resistance genes $b l a_{\mathrm{CTX}-\mathrm{M}-14}$ or $b l a_{\mathrm{CTX}-\mathrm{M}-15}$ [34]. Each isolate was prepared twice, one with gRNA targeting $b a_{\mathrm{CTX}-\mathrm{M}-14}$ and the other targeting $b l a_{\mathrm{CTX}-\mathrm{M}-15}$ (Figure 4 ). The sizes of all the plasmids identified in these three isolates are shown in Figure 4a and the barcodes of the plasmids carrying either the $b l a_{\mathrm{CTX}-\mathrm{M}-14}$ or $b a_{\mathrm{CTX}-\mathrm{M}-15}$ gene are presented in Figure $4 \mathrm{~b}$. All three isolates had plasmids of different sizes and barcodes and we identified no similarity between them. 


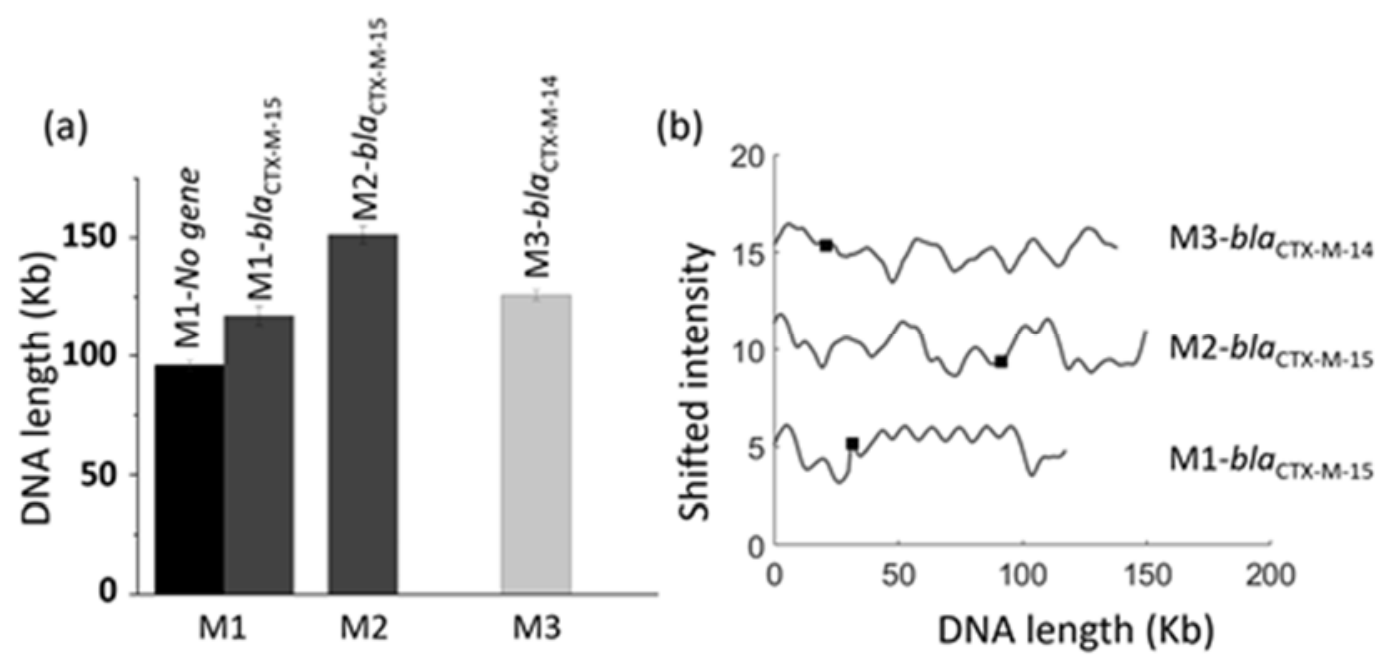

Figure 4. (a) Sizes of plasmids and expected resistance genes found in isolates M1, M2 and M3. (b) Barcodes of plasmids with the bla $a_{\mathrm{CTX}-\mathrm{M}-14}$ or bla $a_{\mathrm{CTX}-\mathrm{M}-15}$ gene in these isolates. Black squares represent the position of the gene. The barcodes are shifted vertically for clarity.

\subsection{Antibiotic Resistance Gene Identification in Clinical Fecal Isolates}

Detection of antibiotic resistance genes located on plasmids in bacterial isolates from clinical specimens can take more than two days if the bacterial colonies are to be first identified and targeted for plasmid extraction. Alternatively, the sample can be directly inoculated into the appropriate medium supplemented with antibiotics suitable for selection of the resistant isolates. Then, after overnight incubation, plasmids can be extracted and purified. However, this approach increases the turnaround time when using conventional methods. Herein, we used a modified enrichment protocol which is four-times faster than the standard enrichment protocol (see Materials and Methods), resulting in the workflow of the whole analysis being reduced to eight hours. The principle of this brief enrichment is to remove irrelevant bacterial species and enrich bacteria carrying the AMR plasmids of interest, thus enabling plasmid extraction from liquid culture instead of bacterial colonies.

We selected five clinical fecal samples (F1-F5) and extracted plasmids using the fourhour enrichment protocol. We performed a polymerase chain reaction (PCR) followed by agarose gel electrophoresis that revealed that F1, F4 and F5 encoded the bla $a_{\mathrm{CTX}-\mathrm{M}-14}$ gene and that all five samples encoded the $b_{\mathrm{CTX}} \mathrm{M}-15$ gene (Figure $5 \mathrm{a}$ ). The quality of sample F4 was not good enough to proceed with the ODM experiments. We investigated the remaining four samples using ODM, each sample being studied for the bla $a_{\mathrm{CTX}-\mathrm{M}-14}$ and $b l a_{\mathrm{CTX}-\mathrm{M}-15}$ genes (Figure 5). In sample F1, two plasmids were found with $b l a_{\mathrm{CTX}-\mathrm{M}-14}$ on a $\sim 96 \mathrm{~kb}$ plasmid and bla $\mathrm{CTX-M-15}$ on a $\sim 85 \mathrm{~kb}$ plasmid, in accordance with the PCR results. The ODM analysis confirmed that the two plasmids were different. Sample F2 had only one plasmid and sample F5 had two plasmids, but ODM suggested that neither of the two resistance genes were located on these plasmids. This could be due to the resistance genes being present in the chromosomal DNA instead. Isolate F3 had a large plasmid $(\sim 200 \mathrm{~kb})$ carrying the bla $a_{\mathrm{CTX}-\mathrm{M}-15}$ gene, in accordance with the PCR results. An important difference between PCR and ODM is that, while the PCR analysis reveals the presence of a specific gene, the ODM analysis determines on which plasmid a specific gene is located. This is important, for example, for epidemiological studies of bacterial transmission [19] and plasmid conjugation [24,26]; we have also shown, previously, that detecting identical plasmids in several samples can be a proxy for ongoing clonal outbreaks $[25,27]$. 


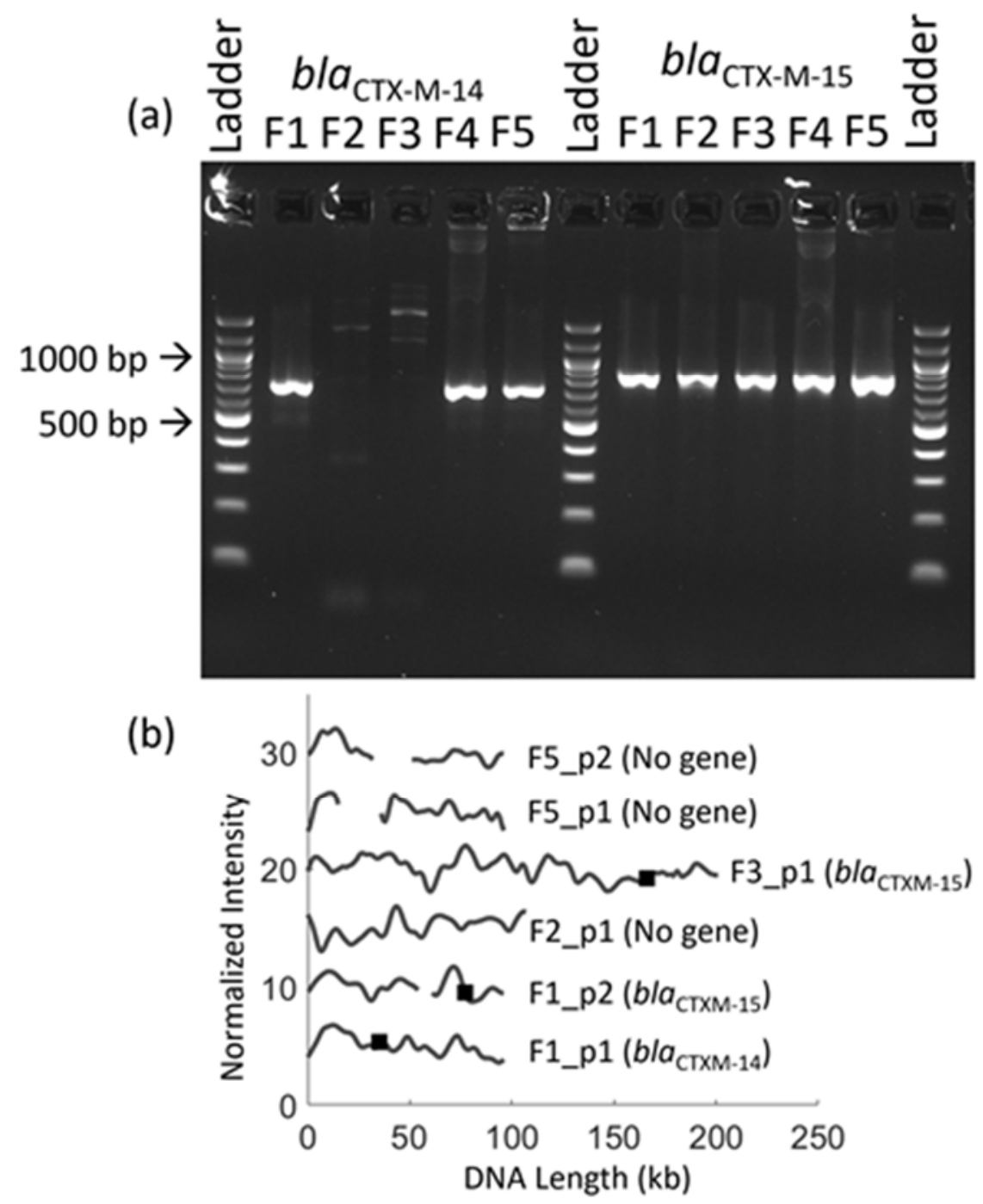

Figure 5. Identification of $b l_{\mathrm{CTX}-\mathrm{M}-14}$ and $b l a_{\mathrm{CTX}-\mathrm{M}-15}$ genes in clinical fecal samples. (a) Results from PCR for clinical fecal isolates F1-F5 for genes bla $a_{\mathrm{CTX}-\mathrm{M}-14}$ and bla $a_{\mathrm{CTX}-\mathrm{M}-15}$. (b) Barcodes for clinical fecal samples F1, F2, F3 and F5 showing the presence or absence of the targeted resistance genes on plasmids, the gene identified and its location (black square) along the DNA barcode. The barcodes are shifted vertically for clarity.

\section{Conclusions}

In this work, we demonstrate the design and fabrication of a nanofluidic chip with ten separately addressable modules, where the device can be filled and images acquired automatically. The device can be used for fundamental studies of the physical properties of DNA, as demonstrated here by simultaneously studying $\lambda$-DNA molecules in buffers of various ionic strengths. More importantly, the device is perfectly suited for simultaneous analysis of many clinical samples, illustrated here by analysis of bacterial plasmids carrying antibiotic resistance genes. The multiplexing can be performed either to study samples from different patients simultaneously, or to analyze the presence of different resistance genes at the same time, or a combination thereof. With our traditional devices with one nanochannel module, one sample can be analyzed per hour. With our new multiplexed and automated chip, ten samples can be analyzed per hour, which drastically reduces the time per sample, and at least a hundred samples could be analyzed per device per day. In a final example, we demonstrate a possible clinical application where we decreased the time for the enrichment of bacteria from fecal samples, which means that the analysis can be completed on the same day the sample is collected. This is a crucial improvement for 
future clinical use of the assay for plasmid analysis, but could also be used for, for example, bacterial identification [21].

Author Contributions: Project conceptualization was carried out by F.W., S.K. and Y.-L.L.; nanofluidic device fabrication was performed by S.K.; bacterial sample handling and plasmid preparation was carried out by T.S. and M.W.; investigation was performed by Y.-L.L. and S.K.; data curation was performed by S.K. and Y.-L.L.; original draft preparation was performed by S.K. and Y.-L.L.; review and editing were carried out by F.W., C.G.G. and L.S.; supervision, project administration and funding acquisition were carried out by F.W., C.G.G. and L.S. All authors have read and agreed to the published version of the manuscript.

Funding: This project was funded by a grant awarded to F.W., C.G.G. and L.S. by the ErlingPersson Foundation.

Institutional Review Board Statement: The use of patient samples was approved by the Swedish Ethical Review Authority (recorded 2018/2735-31/2).

Informed Consent Statement: The informed consent was waived in accordance with the approval from the Ethical Review Authority. Only bacterial DNA was analyzed and no DNA from the patients.

Data Availability Statement: All data and information related to device design/schematics can be obtained from the corresponding author upon reasonable request.

Acknowledgments: The nanofluidic devices used in this work were fabricated at Chalmers MyFab facility. Shoeib Nematzadeh and Muhammad Kabir are acknowledged for assisting with plasmid extraction.

Conflicts of Interest: The authors declare no conflict of interest. The funders had no role in the design of the study; in the collection, analyses, or interpretation of data; in the writing of the manuscript, or in the decision to publish the results.

\section{References}

1. Meng, X.; Benson, K.; Chada, K.; Huff, E.J.; Schwartz, D.C. Optical mapping of lambda bacteriophage clones using restriction endonucleases. Nat. Genet. 1995, 9, 432-438. [CrossRef]

2. Samad, A.H.; Cai, W.W.; Hu, X.; Irvin, B.; Jing, J.; Reed, J.; Meng, X.; Huang, J.; Huff, E.; Porter, B.; et al. Mapping the genome one molecule at a time-Optical mapping. Nat. Cell Biol. 1995, 378, 516-517. [CrossRef]

3. Ebenstein, Y.; Gassman, N.; Kim, S.; Antelman, J.; Kim, Y.; Ho, S.; Samuel, R.; Michalet, X.; Weiss, S. Lighting up individual DNA binding proteins with quantum dots. Nano Lett. 2009, 9, 1598-1603. [CrossRef]

4. Jing, J.; Reed, J.; Huang, J.; Hu, X.; Clarke, V.; Edington, J.; Housman, D.; Anantharaman, T.S.; Huff, E.J.; Mishra, B.; et al. Automated high resolution optical mapping using arrayed, fluid-fixed DNA molecules. Proc. Natl. Acad. Sci. USA 1998, 95, 8046-8051. [CrossRef]

5. Labit, H.; Goldar, A.; Guilbaud, G.; Douarche, C.; Hyrien, O.; Marheineke, K. A simple and optimized method of producing silanized surfaces for FISH and replication mapping on combed DNA fibers. BioTechniques 2008, 45, 649-658. [CrossRef]

6. Müller, V.; Westerlund, F. Optical DNA mapping in nanofluidic devices: Principles and applications. Lab Chip 2017, 17, 579-590. [CrossRef]

7. Sriram, K.K.; Yeh, J.-W.; Lin, Y.-L.; Chang, Y.-R.; Chou, C.-F. Direct optical mapping of transcription factor binding sites on field-stretched $\lambda$-DNA in nanofluidic devices. Nucleic Acids Res. 2014, 42, e85. [CrossRef] [PubMed]

8. Tegenfeldt, J.; Prinz, C.; Cao, H.; Chou, S.; Reisner, W.W.; Riehn, R.; Wang, Y.M.; Cox, E.C.; Sturm, J.C.; Silberzan, P.; et al. The dynamics of genomic-length DNA molecules in 100-nm channels. Proc. Natl. Acad. Sci. USA 2004, 101, 10979-10983. [CrossRef] [PubMed]

9. Zhang, C.; Zhang, F.; A van Kan, J.; van der Maarel, J.R. Effects of electrostatic screening on the conformation of single DNA molecules confined in a nanochannel. J. Chem. Phys. 2008, 128, 225109. [CrossRef]

10. Persson, F.; Tegenfeldt, J.O. DNA in nanochannels-Directly visualizing genomic information. Chem. Soc. Rev. 2010, $39,985$. [CrossRef] [PubMed]

11. Reisner, W.; Pedersen, J.N.; Austin, R.H. DNA confinement in nanochannels: Physics and biological applications. Rep. Prog. Phys. 2012, 75, 106601. [CrossRef] [PubMed]

12. Wang, Y.M.; Tegenfeldt, J.O.; Reisner, W.; Riehn, R.; Guan, X.-J.; Guo, L.; Golding, I.; Cox, E.C.; Sturm, J.; Austin, R.H. Singlemolecule studies of repressor-DNA interactions show long-range interactions. Proc. Natl. Acad. Sci. USA 2005, 102, $9796-9801$. [CrossRef] [PubMed]

13. Nyberg, L.; Persson, F.; Åkerman, B.; Westerlund, F. Heterogeneous staining: A tool for studies of how fluorescent dyes affect the physical properties of DNA. Nucleic Acids Res. 2013, 41, e184. [CrossRef] [PubMed] 
14. Nyberg, L.K.; Persson, F.; Berg, J.; Bergström, J.; Fransson, E.; Olsson, L.; Persson, M.; Stålnacke, A.; Wigenius, J.; Tegenfeldt, J.O.; et al. A single-step competitive binding assay for mapping of single DNA molecules. Biochem. Biophys. Res. Commun. 2012, 417, 404-408. [CrossRef]

15. Gabrieli, T.; Sharim, H.; Nifker, G.; Jeffet, J.; Shahal, T.; Arielly, R.; Levi-Sakin, M.; Hoch, L.; Arbib, N.; Michaeli, Y.; et al. Epigenetic optical mapping of 5-hydroxymethylcytosine in nanochannel arrays. ACS Nano 2018, 12, 7148-7158. [CrossRef]

16. Das, S.K.; Austin, M.D.; Akana, M.C.; Deshpande, P.; Cao, H.; Xiao, M. Single molecule linear analysis of DNA in nano-channel labeled with sequence specific fluorescent probes. Nucleic Acids Res. 2010, 38, e177. [CrossRef]

17. Grunwald, A.; Dahan, M.; Giesbertz, A.; Nilsson, A.; Nyberg, L.K.; Weinhold, E.; Ambjörnsson, T.; Westerlund, F.; Ebenstein, Y. Bacteriophage strain typing by rapid single molecule analysis. Nucleic Acids Res. 2015, 43, e117. [CrossRef]

18. Nilsson, A.N.; Emilsson, G.; Nyberg, L.K.; Noble, C.; Stadler, L.S.; Fritzsche, J.; Moore, E.R.B.; Tegenfeldt, J.O.; Ambjörnsson, T.; Westerlund, F. Competitive binding-based optical DNA mapping for fast identification of bacteria-Multi-ligand transfer matrix theory and experimental applications on Escherichia coli. Nucleic Acids Res. 2014, 42, e118. [CrossRef]

19. Bikkarolla, S.K.; Nordberg, V.; Rajer, F.; Müller, V.; Kabir, M.H.; Kk, S.; Dvirnas, A.; Ambjörnsson, T.; Giske, C.G.; Navér, L.; et al. Optical DNA mapping combined with Cas9-targeted resistance gene identification for rapid tracking of resistance plasmids in a neonatal intensive care unit outbreak. mBio 2019, 10, e00347-19. [CrossRef] [PubMed]

20. Müller, V.; Rajer, F.; Frykholm, K.; Nyberg, L.K.; Quaderi, S.; Fritzsche, J.; Kristiansson, E.; Ambjörnsson, T.; Sandegren, L.; Westerlund, F. Direct identification of antibiotic resistance genes on single plasmid molecules using CRISPR/Cas9 in combination with optical DNA mapping. Sci. Rep. 2016, 6, 37938. [CrossRef] [PubMed]

21. Müller, V.; Nyblom, M.; Johnning, A.; Wrande, M.; Dvirnas, A.; Kk, S.; Giske, C.G.; Ambjornsson, T.; Sandegren, L.; Kristiansson, E.; et al. Cultivation-free typing of bacteria using optical DNA mapping. ACS Infect. Dis. 2020, 6, 1076-1084. [CrossRef] [PubMed]

22. Müller, V.; Dvirnas, A.; Andersson, J.; Singh, V.; Kk, S.; Johansson, P.; Ebenstein, Y.; Ambjörnsson, T.; Westerlund, F. Enzyme-free optical DNA mapping of the human genome using competitive binding. Nucleic Acids Res. 2019, 47, e89. [CrossRef]

23. World Health Organization. Global Action Plan on Antimicrobial Resistance; World Health Organization: Geneva, Switzerland, 2015.

24. Karami, N.; Kk, S.; Yazdanshenas, S.; Lin, Y.-L.; Jaén-Luchoro, D.; Ekedahl, E.; Parameshwaran, S.; Lindblom, A.; Åhrén, C.; Westerlund, F. Identity of blaCTX-M carrying plasmids in sequential ESBL-E. coli isolates from patients with recurrent urinary tract infections. Microorganisms 2021, 9, 1138. [CrossRef] [PubMed]

25. Kk, S.; Sewunet, T.; Wangchinda, W.; Tangkoskul, T.; Thamlikitkul, V.; Giske, C.G.; Westerlund, F. Optical DNA mapping of plasmids reveals clonal spread of carbapenem-resistant Klebsiella pneumoniae in a Large Thai hospital. Antibiottics 2021, 10, 1029. [CrossRef]

26. Lindblom, A.; Kk, S.; Müller, V.; Öz, R.; Sandström, H.; Åhrén, C.; Westerlund, F.; Karami, N. Interspecies Plasmid Transfer Appears Rare in Sequential Infections with Extended-Spectrum B-Lactamase (Esbl)-Producing Enterobacteriaceae; Elsevier: Amsterdam, The Netherlands, 2019; Volume 93, p. 6.

27. Lin, Y.-L.; Sewunet, T.; Kk, S.; Giske, C.G.; Westerlund, F. Optical maps of plasmids as a proxy for clonal spread of MDR bacteria: A case study of an outbreak in a rural Ethiopian hospital. J. Antimicrob. Chemother. 2020, 75, 2804-2811. [CrossRef]

28. Öz, R.; Kk, S.; Westerlund, F. A nanofluidic device for real-time visualization of DNA-Protein interactions on the single DNA molecule level. Nanoscale 2019, 11, 2071-2078. [CrossRef] [PubMed]

29. Dvirnas, A.; Pichler, C.; Stewart, C.L.; Quaderi, S.; Nyberg, L.K.; Müller, V.; Bikkarolla, S.K.; Kristiansson, E.; Sandegren, L.; Westerlund, F.; et al. Facilitated sequence assembly using densely labeled optical DNA barcodes: A combinatorial auction approach. PLoS ONE 2018, 13, e0193900. [CrossRef] [PubMed]

30. Alizadehheidari, M.; Werner, E.; Noble, C.; Reiter-Schad, M.; Nyberg, L.K.; Fritzsche, J.; Mehlig, B.; Tegenfeldt, J.O.; Ambjörnsson, T.; Persson, F.; et al. Nanoconfined circular and linear DNA: Equilibrium conformations and unfolding kinetics. Macromolecules 2015, 48, 871-878. [CrossRef]

31. Iarko, V.; Werner, E.; Nyberg, L.K.; Müller, V.; Fritzsche, J.; Ambjörnsson, T.; Beech, J.; Tegenfeldt, J.; Mehlig, K.; Westerlund, F.; et al. Extension of nanoconfined DNA: Quantitative comparison between experiment and theory. Phys. Rev. E 2015, $92,062701$. [CrossRef]

32. Lee, S.; Lee, Y.; Kim, Y.; Wang, C.; Park, J.; Jung, G.Y.; Chen, Y.; Chang, R.; Ikeda, S.; Sugiyama, H.; et al. Nanochannel-confined TAMRA-polypyrrole stained DNA stretching by varying the ionic strength from micromolar to millimolar concentrations. Polymers 2018, 11, 15. [CrossRef]

33. Reisner, W.; Morton, K.J.; Riehn, R.; Wang, Y.M.; Yu, Z.; Rosen, M.; Sturm, J.C.; Chou, S.Y.; Frey, E.; Austin, R.H. Statics and dynamics of single DNA molecules confined in nanochannels. Phys. Rev. Lett. 2005, 94, 196101. [CrossRef] [PubMed]

34. Brolund, A.; Rajer, F.; Giske, C.G.; Melefors, Ö.; Titelman, E.; Sandegren, L. Dynamics of resistance plasmids in extendedspectrum- $\beta$-lactamase-producing enterobacteriaceae during postinfection colonization. Antimicrob. Agents Chemother. 2019, 63, e02201-18. [CrossRef] [PubMed] 